\title{
Multicultural markets and acculturation: implications for service firms
}

\author{
Konstantinos Poulis \\ University of Essex, Essex Business School, Southend-on-Sea, United Kingdom \\ Mo Yamin \\ The University of Manchester, Manchester Business School, Manchester, United Kingdom, and \\ Efthimios Poulis \\ University of East Anglia - Norwich Business School, London, United Kingdom
}

\begin{abstract}
Purpose - The purpose is to construct an analytical framework that encapsulates implications for the marketing offering of service firms as a result of observed intra-national ethnic diversity in these firms' markets of operation.

Design/methodology/approach - This is a conceptual approach which promotes the idea that acculturation matters for service firms operating in multicultural markets and adopts relevant propositions related to service firms' strategy in such markets.

Findings - Integrating fragmented insights from consumer behaviour and multicultural marketing, the study suggests that the various interactions and contacts between ethnic groups in a multicultural country can generate acculturation outcomes that lend themselves to novel avenues for empirical research. These avenues move beyond a research focus on the presence of ethnic groups as stand-alone entities of intra-ethnic uniformity.

Practical implications - Firms with a broader market horizon in a multicultural market can employ acculturation in their marketing strategy since an exclusive focus on ethnicity as a basis of segmenting the market reveals shortcomings. Otherwise, a myopic approach that ignores cross-ethnic interactions may lead to bypassing opportunities for more considerate market responses by a service firm.

Originality/value - To the best of the authors' knowledge, this is the only acculturation study in a services context that offers an analytical framework and propositions that can be used as a guide for multicultural, services marketing researchers and practitioners that see the market in a holistic fashion.
\end{abstract}

Keywords Acculturation, Ethnic marketing, Multicultural marketing

Paper type Conceptual paper

An executive summary for managers and executive readers can be found at the end of this article.

\section{Introduction}

The literature acknowledges the interconnectedness of people across the world through various manifestations of crosscultural flows and/or physical mobility of individuals (Appadurai, 1990; Berry, 2003; Poulis and Poulis, 2012). As a result, politically defined boundaries do not coincide with ethnically homogeneous societies. This intra-national ethnic diversity (henceforth described as INED) is understood in this study as diversity stemming from the coexistence of different ethnic groups as permanent or long term residents in one country (Ogden et al., 2004).

The prevalence of INED and its prima facie significance to marketing strategy - notwithstanding the literature on multicultural marketing - has not received what it arguably merits and remains underdeveloped (Burton, 2002; Lenartowicz et al., 2003; Poulis and Yamin, 2009; Seggie and Griffith, 2008). More specifically, fragmentation and lack

The current issue and full text archive of this journal is available at www.emeraldinsight.com/0887-6045.htm

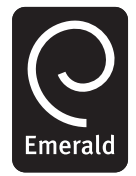

Journal of Services Marketing

27/7 (2013) 515-525

(C) Emerald Group Publishing Limited [ISSN 0887-6045]

[DOI 10.1108/JSM-02-2012-0041] of insights seems to be amplified in certain service industries. This may be understandable in some services contexts (e.g. professional services) which are not normally associated with culture and minorities' relationships with majority populations. However, surprisingly, there is dearth of research even in services sectors which are fundamentally susceptible to cultural influences such as advertising (Briggs et al., 2010; Torres and Briggs, 2005) and also in services sectors of a utilitarian nature (e.g. financial services; Neilson and Chadha, 2008). Overall, what one can observe is that, despite notable papers that discuss cultural issues in services (Perry, 2008; Blankson and Kalafatis, 2007; Mattila, 1999), the services multicultural marketing literature reveals some gaps and shortcomings. Below, we explain how these lend themselves to the current paper, we describe a fundamental disconnect between consumer behaviour and services marketing literatures and we attack the problem from an acculturation perspective noting that "understanding acculturation processes is more important than ever" for marketing (Steenkamp, 2001, p. 38).

\section{The disconnect in the literature}

On the one hand, the consumer behaviour literature (Lerman et al., 2009; Ogden et al., 2004), in explaining ethnic

Received 10 February 2012

Revised 1 August 2012

Accepted 20 August 2012 
consumers' behaviour, stresses the importance of acculturation i.e. the process of cultural change or maintenance whenever individuals from diverse cultures interact (Gibson, 2001). We can infer from this literature that interactions between ethnic groups are an ongoing, permanent process and that patterns of acculturation within ethnic groups are not homogeneous since "ethnic" consumers form their identities through diverse acculturation modes. However, on the other hand, the services marketing literature almost exclusively relies on an ethnic approach that is premised on an (often empirically invalid) high degree of intra-ethnic uniformity and sameness (Briggs et al., 2010; Neilson and Chadha, 2008; Shanmuganthan et al., 2003; Torres and Briggs, 2005). Several studies, thus, treat the ethnic group as an isolated segment, focusing on the distinctive features and the particular ethnic identification of, e.g. Hispanics. Fragmented yet increasing indications though, showcase that interaction between different ethnic groups and diverse acculturation outcomes may render ethnic identity less relevant for services firms resulting in heterogeneous consumption behaviours within ethnic groups (Klemm and Kelsey, 2004; Perry, 2008; Sharma et al., 2009). For example, some Pakistani consumers in the UK will be assimilated and "consume" same entertainment services with British consumers while other Pakistani consumers will be separated and remain attached to entertainment services that are reminiscent of their home culture.

Therefore, there is a conceptual disconnect which needs to be addressed; if insights from consumer behaviour are valid then, the services marketing literature needs to acknowledge acculturation's role and align firm's strategies with the realities $v i s-\grave{a}$-vis inter-ethnic acculturation processes. Currently though, this is not the case. We do not underestimate the role of ethnicity; on the contrary, we acknowledge its value but we seek to tease out conceptually how interaction among ethnicities (rather than their mere presence) resulting to diverse acculturation outcomes may extend the boundaries of relevant services marketing studies.

Moreover, while the focus of ethnic or ethnic-related studies on the behaviour and attitudes that ethnic consumers adopt is large and well-established, the literature lacks offering managerial implications for firms marketing their services and products in multicultural markets (Burton, 2000; Poulis and Poulis, 2012). This study is thus an addition to a series of works (e.g. Bhalla et al., 2006; Iyer and Shapiro, 1999) which have explored firms' marketing praxis in such contexts. Certainly, the question of firms' perception regarding the appropriate strategy in such contexts is an empirical one and thus, cannot be answered in this conceptual approach. Therefore, more specifically, the objective of this study is built upon Burton (2000) and Lerman et al. (2009) who note the importance of addressing the implications of varying acculturation outcomes for marketing decisions and, in particular in this study, for service firms' offerings towards a multicultural consumer base.

\section{Multicultural services marketing: some observations}

Despite recent calls for a more pluralistic methodological arsenal in the overall multicultural marketing research (Slater and Yani-de-Soriano, 2010), the latter body has traditionally followed the dominant methodological backdrop of marketing research, i.e. it is quantitative-driven with surveys being the most widely used method of investigation (Burton, 2002; Poulis et al., n.d.). A turning point in the adoption of alternative methodological devices has been Penaloza's (1994) paper which opened up the path for more qualitative, in-depth studies exploring issues of acculturation and ethnicity. It provided an insightful view on the "how" behind the acculturation processes of Mexican immigrants in the US as opposed to the measurement-driven studies that dominated the field before that. Building upon such seminal papers, the last two decades have seen an increase in qualitative investigations in multicultural marketing research, which include ethnographies and in-depth interviews with paradigmatic respondents (Sekhon and Szmigin, 2011; Lindridge and Hogg, 2006).

More specifically though, the multicultural services marketing discourse has explored relevant issues through a variegated portfolio of methodological approaches including online surveys (Miyazaki et al., 2007), quasi-experimental designs (Torres and Briggs, 2005), surveys (Stevenson and Plath, 2006), dividend capitalisation method (Hearn et al., 2012), content analysis (Briggs et al., 2010), interviews (Perry, 2008), focus groups (Klemm and Kelsey, 2004) and mixed methods (Omar et al., 2003). Thus, research designs that are used in order to investigate multicultural marketing issues in the services sector cover a wide spectrum of qualitative and quantitative modes relying on both primary and secondary data across multiple and more narrowly-defined numbers of organisational and consumer respondents.

Despite this methodological plurality though, we observe four shortcomings that characterise the multicultural services marketing literature and imply respective gaps. These lend themselves to the development of a body of distinct yet interrelated propositions which help in opening up the discussion on how concepts such as culture, ethnicity and acculturation can more meaningfully enrich the services marketing discourse.

\section{Observation 1: imbalance between inter- and intra- national studies}

Most papers in multicultural services adopt an inter-national (e.g. Grandey et al., 2010; Javalgi and Martin, 2007; Furrer et al., 2000) rather than an intra-national multicultural focus. This uneven development seems to follow the assumption that inter-national differences are more salient than intra-national, cultural interactions. Without denying the importance of inter-national investigations for services firms, we note that the marketing literature explicitly showcases the importance of intra-national, cultural interactions across various sectors (Pires and Stanton, 2000; Poulis and Yamin, 2009; Briggs et al., 2010), which generate significant implications for both domestic and foreign firms (Poulis et al., 2012). Therefore, there is a remarkable imbalance in the services literature between inter- and intra-national investigations, which renders further research on the latter as an imperative.

Observation 2: neglecting ongoing interactions between ethnically diverse consumers

Most multicultural services studies (e.g. Miyazaki et al., 2007; Stevenson and Plath, 2006; Plath and Stevenson, 2005) approach ethnic groups (e.g. Hispanics) as distinct from 
others (e.g. non-Hispanics) and compare behaviours between an ethnic group and the rest of the consumer base or suggest ethnic-based opportunities and strategies around ethnic groups (Shanmuganthan et al., 2003). We do not deny the value of such comparative and ethnic-focused investigations. However, such a research stance, despite its benefits, implies an isolation between majority and minority populations which neglects the ongoing interactions/contacts between them (Berry, 1997; Sharma et al., 2009). An important issue for the service literature is that consumers' interactions in multicultural markets (rather than a mere comparison of seemingly detached individuals) give rise to distinct acculturation outcomes which render ethnicities (and hence comparisons across ethnicities) less relevant for marketing purposes. By employing the concept of acculturation, we aim at demonstrating the importance of these interactions more succinctly.

\section{Observation 3: lack of cross-pollination between multicultural services marketing and social psychology literatures}

Despite the documented effect of social psychological constructs such as acculturation on multicultural marketing practices, there seems to be limited fertilisation of the services field with insights from the established acculturation literature. This can also be inferred from the use of related nomenclature in services marketing papers (e.g. Stevenson and Plath, 2006; Omar et al., 2003, p. 81), i.e. the fact that acculturation is often treated as synonymous with assimilation and understood as "[...] the process of acquiring the customs of an alternative society". This "assimilationist" view of acculturation is challenged since acculturation denotes several outcomes beyond mere assimilation (please refer to the rest of the paper for more discussion about this evolutionary understanding of acculturation dimensions). Moreover, in the exceptional cases where acculturation is discussed in a services context, this happens at either the customer or employee (Sharma et al., 2009) but not at the firm, decision-making level (Klemm and Kelsey, 2004), which is this paper's focus.

\section{Observation 4: limited breadth of research scope}

In general, authors caution about the limited breadth and scope of multicultural marketing investigations across diverse sectors (Ogden et al., 2004). This echoes more context-specific concerns in the services literature (Pires and Stanton, 2000) whose most multiculturalism-related papers have been limited to specific geographical and industry contexts such as, e.g. the North American/North European financial services industries (e.g. Plath and Stevenson, 2005; Shanmuganthan et al., 2003). As a result, the services literature has plenty of scope to revisit multicultural marketing issues and expand the boundaries of relevant investigations. This seems increasingly important given that multiculturalism is an inherent part of both developed and developing countries' societal structures.

These observations reveal challenges for service firms' strategy formulation if such strategy is to take full cognisance of the ramifications of acculturation. Thus, methodologically and conceptually, there is scope for tailored inquiry and new analytical frameworks. Overall, these observations lend themselves to more considerate conceptual and empirical research approaches. Thus, this paper endeavours to conceptualise the implications of INED for marketing services to ethnic consumers, a field which is disproportionately developed compared to other services marketing fields (Pires and Stanton, 2000). We adopt an analytical focus on firms' service options in a multicultural market and develop propositions relating to "broad" or "niche" strategies based on acculturation categories, i.e. consumers are "re-assembled" into segments on the basis of a common acculturation pattern (and not their ethnic group).

\section{Understanding ethnicity}

The literature, through a multiparadigmatic approach that spans diverse disciplines such as sociology, psychology and management, has early offered a plethora of conceptualisations of ethnicity. According to authors such as Weber (1968), Yinger (1985) and Feagin and Feagin (1996), ethnicity is an element that binds people into one collectivity either due to subjective beliefs about a common ancestry or because of objective similarities in appearance, customs, language, preferences and memories that are shared across ethnic individuals. These commonalities gradually shape a taught culture, which is largely idiosyncratic and acts as an antecedent to aspects of civic and consumer behaviour. Geertz (1963) stresses the self-identification element in defining ethnicity and pinpoints to the desire of individuals to voluntary belong to a specific ethnic group. Therefore, ethnicity is not a fixed and given property but rather an identity that is individually felt and enacted by particular environmental contingencies (Cleveland et al., 2009).

Based on the previous point, individuals can belong to or identify with a particular ethnic group (Cleveland et al., 2009) allowing authors to broadly view ethnicity in two ways (Laroche et al., 1998): on the one hand, ethnic origin refers to a nominal and quite often arbitrary categorisation that is useful for classification purposes. On the other hand, ethnic identity refers to the multidimensional construal of a self which is associated with the norms and values of a particular ethnic group. Ethnic identity is constructed since early childhood as a result of a contrast between a particular ethnic group and the "others". These contrasting patterns enable the awareness of one's own ethnic self and result to learned behaviours that develop over time (Lambert and Klineberg, 1967; Phinney, 1990). The contribution and role of institutions such as the family or religion are instrumental in the course of this contrasting, developmental process.

Following on from the aforementioned observation, an important point to note in the context of this study is that attempts to define ethnic identity cannot be seen in a fragmented, stand-alone way. Rather, ethnic identity is understood in relation to the "other" (Roosens, 1989) and starts making sense when seen in a context of co-existence or parallel living of different ethnic groups. Essentially, therefore, ethnicity is a relational construct; an observation, which reflects the construction of one's own ethnic identity through interaction and engagement with other identities. In such a relational context, cultural components of ethnic identity such as language, consumption preferences or participation in social activities and friendship networks are accentuated or constrained resulting to numerous self-construals of ethnic identity (Burton, 2000; Jamal, 2003). 
This plethora of outcomes can be attributed to the enduring role of ethnicity that does not exclusively lead the individual towards eventual assimilation (Burton, 2000), but also the interaction of ethnicities and the formed interpersonal networks as factors that influence consumers' behaviour in multiple ways (Granovetter, 1985) (and consequently, firms' strategy). Despite the early tendency of some multicultural societies to assimilate ethnic individuals, the latter often exhibit Gestalts of resistance to catholic assimilation and acculturate in diverse ways either rejecting or maintaining aspects of their ancestral culture. Therefore, exploring multicultural societies in order to surmise implications for managerial practice implies that acculturation forces must be seen in conjunction with ethnicity (Laroche et al., 1998). Given that an individual's identity is subject to construction and re-construction (Granovetter, 1985) following ongoing interactions with the ethnic "other", the service firm must broaden its understanding of the market beyond either exclusively assimilationist or exclusively separatist paradigms. The following section on acculturation aims to explicate its constituent characteristics further and stress the implications for the marketing strategy of service firms.

\section{The nature and role of acculturation: Berry et al.'s contribution}

Early works perceived acculturation as a linear progression from arrival to assimilation with the host culture (Gordon, 1964). Thus, the assumption was that "incoming" ethnic groups become fully integrated into the host culture with acculturation becoming "synonymous with assimilation" (Berry, 1997, p. 7). Later though, linear acculturation was refuted (Wallendorf and Reilly, 1983; Jun et al., 1993) with studies challenging the idea that ethnic groups are eventually assimilated by the society in which they reside (Gibson, 2001; Berry, 1997). Otherwise, due to an eventual assimilation of minority groups, diversity would not be of significant interest for firms (since ethnic diversity would have no significant impact on how firms would define their markets). However, acculturation outcomes beyond assimilation are noted following decades of acculturation research from a sociological (Devereux and Loeb, 1943), psychological (Coleman, 1995) or social psychology perspective (Brubaker, 2001).

Out of all these contributions, perhaps the most cited model of acculturation is found in Berry et al. (1986), Berry (1997) and Berry (2003) and it is utilised in this study, too. Apart from its intuitive sense and much-cited appeal, Berry's model offers a straightforward logic for services marketing, too; a service firm's strategy with broad horizons is dictated by a view on the market and not on the individual user of services. Thus, acculturation studies that focus on the individual have less relevance for this paper whereas Berry's model accurately describes acculturation processes at group levels (Ogden et al., 2004), i.e. the analytical foci of this paper. Thus, the majority of acculturation models routinely resemble Berry's categories (e.g. Unger et al. 2002; LaFromboise et al., 1993; Triandis et al. 1986).

The model depicts how ethnic groups' interactions lead to acculturation categories in multicultural contexts. The acculturation process engenders amongst members of an ethnic group either positive or negative stances with respect to "ancestral" and "host" cultures. On the one hand, the model
Volume $27 \cdot$ Number $7 \cdot 2013 \cdot 515-525$

indicates that individuals may or may not strive for cultural maintenance. This stance reflects the extent to which individuals consider their cultural identity as important and decide to maintain it. On the other hand though, individuals may or may not strive for contact and participation, too. This latter stance reflects the extent to which an individual's involvement with the majority culture is attempted. This dual approach towards maintaining one's own cultural background and/or endeavouring to intermingle and engage with the host/ dominant culture implies a configuration of positive and negative stances which are reflected in Table I. The horizontal dimension in the table relates to either a positive or negative stance towards the home (minority) culture and captures the extent to which (or whether) individuals remain attached to their ancestral culture and choose to preserve it (i.e. the degree of cultural ancestry retention). The vertical dimension in the table relates to either a positive or negative stance towards the host (majority or dominant) culture and thus, captures the extent to which (or whether) individuals embrace the host culture (i.e. the degree of host culture acceptance).

Configuring these positive/negative stances towards the home and host cultures respectively gives rise to four modes of acculturation, which are the following: Integration comes into play whenever individuals both maintain their ancestral culture and participate eagerly in the host culture. Assimilation takes place whenever ancestral culture is rejected and an active engagement with the host culture is attempted at the same time. Separation describes the process through which individuals preserve their ancestral cultural identity and simultaneously are not keen on engaging with the host culture whereas marginalisation refers to the case when both the ancestral and host cultures are rejected by the individuals. At this point, we must note that we do not ignore the fact that acculturation for the individual is not fixed but instead entails diverse behavioural and affective stances which are determined by context (Oswald, 1999). However our purpose is not to understand how inter-ethnic contact and acculturation may construct or maintain multiple identities for the individual user of services but rather it is to explore the possible implications of the modes of acculturation for service firms' marketing strategy. Thus, we proceed by asking how the modes of acculturation may impact firms' assessment of an appropriate strategic posture.

We believe our approach is justified as acculturation is found to influence marketing practices of firms (Chattalas and Harper, 2007; Palumbo and Teich, 2004) yet its implications for practice are under-theorised. Overall, benefits of employing acculturation for theory and practice-related purposes include the following: The observation that acculturation outcomes have a stronger effect on consumers' behaviour than ethnicity (Ownbey and Horridge, 1997) implies that theorising needs to move beyond exclusive ethnic-focused investigations and consider interactions across

Table I Modes of acculturation

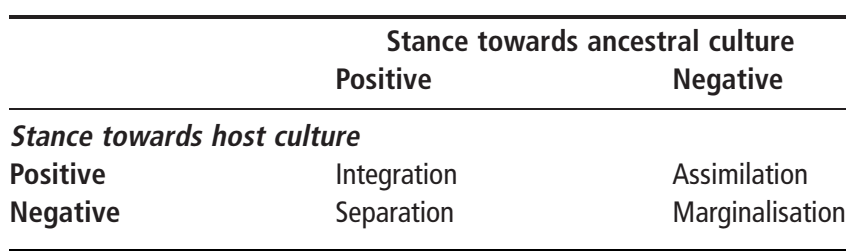


ethnicities. Specifically, Berry's acculturation categories have been found to represent different segments and thus, service practitioners can tailor their offering towards targeted acculturation groups (as opposed to ethnic groups). For example, Lerman et al. (2009) and Korgaonkar et al. (2000) highlight that in the context of advertising services with same or tailored advertising themes targeted towards assimilated versus non-assimilated consumers (as opposed to, e.g. Hispanics versus non-Hispanics). Finally, the understanding that ethnicity is not a fixed property but rather a fluid occurrence which results to multiple acculturation outcomes (Oswald, 1999) implies that acculturation-based research has a greater potential to capture the multidimensional Gestalts of ethnic identification that may be observed in a market. After all, acculturation is a socialisation process which may further embed in or further alienate an individual from his/her ethnic context (Ogden et al., 2004). On the contrary, treating ethnicity as a fixed, unchanged property that accompanies the individual throughout his/her life does not realistically reflect the dynamic nature of consumers' various predispositions and evolving choices.

\section{A conceptual framework for the role of acculturation in a multicultural services context}

Figure 1, at the end of this section, illustrates the conceptual framework which underpins this paper and reflects consequent propositions. The co-existence of ethnicities in a country creates a mosaic, which generates INED and gives rise to what is typically known as a multicultural market (left box in Figure 1). However, as explained before, ethnicity is essentially a relational construct; thus, ethnicities that induce such markets do not simply reside in a market context but rather intermingle and through their ongoing interactions, they co-construct distinct categories of acculturation (central box in Figure 1) which map onto different possibilities for services firms' strategies in multicultural markets (right box in Figure 1). These strategies are seen as a continuum of alternatives ranging from extreme forms of a "replicated" offering up to extreme forms of "invention" (please see below
Volume $27 \cdot$ Number $7 \cdot 2013 \cdot 515-525$

for a definition of the different strategies identified in the right box).

It is also worthwhile to note that services do not represent a universal and uniform industry structure (that of services broadly speaking) but rather each services sector is often a stand-alone setting that reflects idiosyncratic, context-specific characteristics within the broader services industry "family". For example, entertainment or advertising lend themselves to value-expressive offerings to users of such services while others such as banking reflect utilitarian expectations (Perry, 2008). Similarly, high and low involvement service brands present dissimilar characteristics and thus, marketing implications for serving ethnic consumers vary across both contexts (Torres and Briggs, 2005). Therefore, one should expect that different service industries will be differently affected by acculturation outcomes. The top box in Figure 1 ("Nature of Services Context") aims to highlight this effect that the nature of a service industry may have on the relationship between acculturation categories and the choice of marketing strategy by a service firm. Thus, we put forward the following proposition:

P1. The effect of acculturation outcomes on service firms' offering in markets that are characterised by INED will vary depending on the nature and idiosyncratic features of each service context.

We are also aware of an important caveat. Acculturation processes are in practice shaped by particular national contexts, themselves reflecting history and institutional drivers (Freedman, 2001; Laroche et al., 1998) whereas in some cases, users of services (e.g. insurance and pension schemes, Burton, 2000) are obliged to conform to assimilationist norms imposed by the majority culture. Thus, in some countries, the acculturation outcomes may flow, not only from the "free" or autonomous interactions between ethnicities but also from policy-makers who, driven by ideology and political power, may be "imposing" their assimilationist agendas (Parekh, 2000; Burton, 2009). For example, in the US, in early 1900, there were attempts to "Americanise" immigrants due to nationalistic views that the latter represented a threat to American culture (Ogden et al., 2004). Due to this road towards eventual homogenization, an

Figure 1 Conceptual framework of the role of acculturation in a multicultural services context

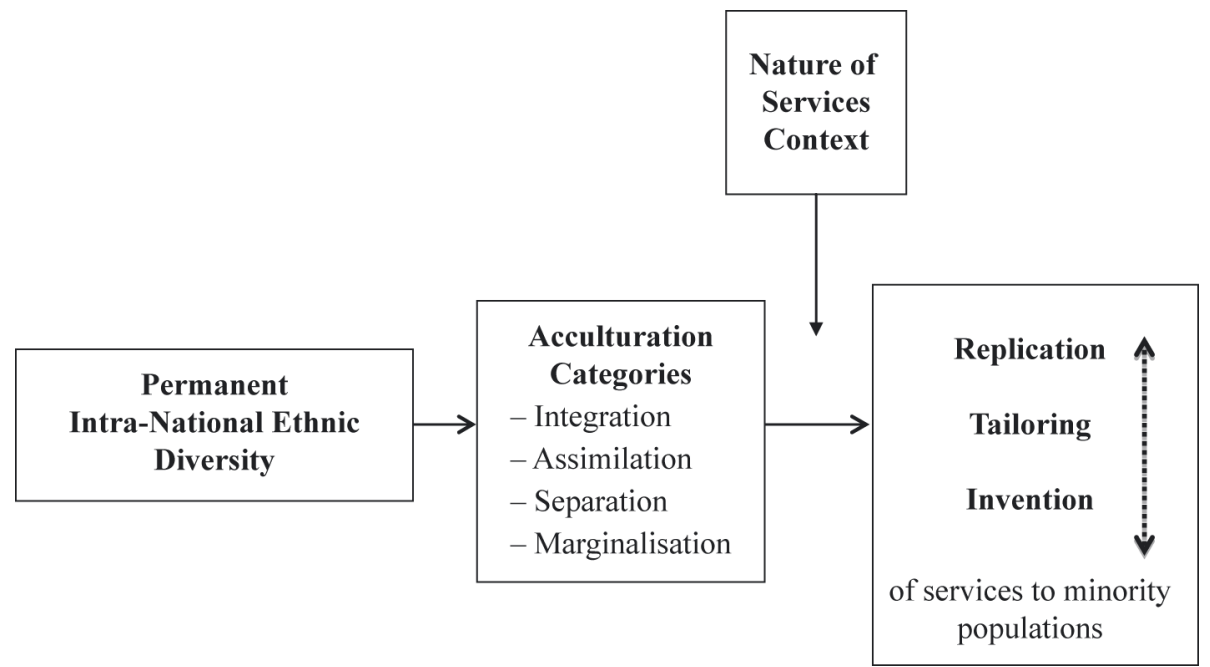


acculturation approach may become less relevant since acculturation possibilities are narrowed down to assimilation only. Therefore, our study, which stresses the open possibilities for different outcomes of acculturation is more relevant in market contexts whose political and institutional frameworks emphasize cultural plurality and free interactions among majority and minority populations (e.g. USA, UK).

\section{Services marketing strategy in multicultural markets}

In multicultural markets, an analytically important question is whether ethnic groupings within the national boundary that are in the marketing "preview" of services firms can be treated on a common basis. Apparently, this will have cost saving advantages arising from adopting a shared service "platform" across ethnic subgroups. Potential cost advantages of a common approach would of course, be evaluated against perceived disadvantages arising from disregarding ethnic heterogeneities. In other words, for service firms with broad marketing horizons the issue is one of using same, tailored or new strategies towards ethnic consumers.

We develop this further by linking the pattern of INED with the acculturation process and we derive propositions regarding service firms' strategies by adopting the following definitions: service replication in a domestic context characterised by INED denotes offering members of minority cultures the same services as those offered to the majority culture. Service tailoring in a domestic context characterised by INED denotes offering members of minority cultures tailored services compared to those offered to the majority culture. Service invention in a domestic context characterised by INED denotes offering members of minority cultures new services compared to those offered to the majority culture.

Thus, clearly, if users of services in a country tend towards an assimilation stance then, a policy of "replication" is favoured. For example, literature insights from the travel (Klemm and Kelsey, 2004) and media/entertainment (O'Guinn and Meyer, 1984) services sectors indicate that assimilated ethnic consumers in the UK and the US respectively prefer same travel services and listen to mainstream, "Anglo" radio thus, connoting the plausibility of adopting "replication" strategies. This is not to claim that differences in ethnicity do not exist. These may indeed exist if one adopts objective measures of ethnicity (e.g. appearance or language) but nevertheless, the voluntary decision of assimilated consumers to adopt the norms and consumption behaviours of the majority culture does not justify a "tailored" or "invention" approach (whereas a "replication" approach offers cost-related benefits, too).

Indeed, individuals often assimilate and exhibit this stance in their consumption choices because they, otherwise, feel alienated. The cultural shift that assimilated immigrants develop in the US or Canada may reflect a process that restores normality and acts as a psychological strategy of "legitimisation", reduction of stress and harmonious citizenship in the host society (Ogden et al., 2004; Olsen, 1995). Therefore, immigrants who demonstrate a "mutation" of their cultural narrative and adopt assimilationist behaviours are more proactive in shaping relationships with host, dominant cultures; a stance that is reflected in their consumption preferences, too. As research has shown
Volume $27 \cdot$ Number $7 \cdot 2013 \cdot 515-525$

(Maldonado and Tansuhaj, 2002), they tend to favour brands which are offered to the majority population since the latter population acts as the main reference group for assimilated consumers' choices. Thus, we propose:

P2. The more the assimilated members of minority cultures in a multicultural market, the greater the degree of service replication (relative to service tailoring or service invention) in a service firm's offering.

"Integrated" consumers are portrayed as feeling comfortable with offerings that reflect both majority and minority preferences (Lerman et al., 2009) while literature has shown that certain types of immigrants (e.g. second-generation Indians in the UK) are inclined to adopt "dual", integration features in their consumption behaviour stemming from an empathy and familiarisation with both home and host contexts (Sekhon and Szmigin, 2011). Moreover, Maldonado and Tansuhaj (2002) note that consumers in the integration category have been found to prefer host and ethnic brands in similar proportions, with attendant implications for firms.

More specifically, by integrating fragmented yet insightful observations from the services literature, one can surmise that both "replicated" and "tailored" services could be the market response to integrated consumers. More specifically, there are indications that integrated consumers require services that have both same aspects with those for the dominant, majority culture and aspects geared towards ethnic idiosyncrasies (for example, in financial services; Stevenson and Plath, 2006). At the same time, other insights (for example, in travel services; Klemm and Kelsey, 2004) suggest that integrated consumers behave in the same way as the majority population does and thus, they expect exactly the same services. Therefore, fragmented empirical findings collectively indicate that there is a continuum of service alternatives ranging from "tailored" to "replicated" services.

Consequently, if we adopt a customer-driven approach, no concrete, prescriptive outcome can be suggested but rather the service offering will swing like a pendulum between "replication" and "tailoring" with the eventual decision being based on each given context. Utilizing elements of both home and host cultures (i.e. tailored service offerings) seems to facilitate greater acceptance of services by integrated minority consumers (Stevenson and Plath, 2006) mostly in culture-bound service industries (Shanmuganthan et al., 2003) where different cultural make-ups are found to respond differently to service offerings (Zhang et al., 2008).

However, there is an important point to consider: a focus on integrated consumers' comfort with "tailored" strategies neglects the strong effect of intra-organisational concerns and specifically, the quest for cost efficiencies. This concern is especially noted in services sectors and it has to be woven into this discussion. For example, Keaveney (1995) notes that price is a main reason that leads customers to switch service providers. Overall, service research has stressed the negative effect that higher prices have on purchasing intentions (Dawes, 2009; Varki and Colgate, 2001; Voss et al., 1998). Therefore, there is also a certain pressure to services firms to reduce costs, which are normally associated with "tailored" or "invented" approaches. For the same reasons, firms strive to avail of cost efficiencies, which are obviously better achieved through "replicated" practices. Thus, cost considerations, in 
addition to integrated consumers' comfort with "replicated" offerings, may lead to higher levels of such offerings in contexts where a high number of price-sensitive integrated minority consumers exists. In other words, demand elasticity and hence, service firms' cost considerations need to be considered in conjunction with the culture-bound nature of specific service industries. This is because all determine the effect of perceived integrated consumers' expectations on "replicated" or "tailored" strategies of service firms.

The following propositions reflect these observations whenever integrated consumers seem to be dominant in a multicultural market and they approach service strategies as a continuum of alternatives rather than a clear-cut prescription of one strategy versus the other:

P3a. In a multicultural market, the more the integrated consumers and the higher the price elasticity of demand, the more sway towards service replication (relative to service tailoring) and vice versa.

P3b. In a multicultural market, the more the integrated consumers and the higher the culture-bound nature of the focal service, the more sway towards service tailoring (relative to service replication) and vice versa.

Propositions, so far, reflect the advantage of "replication" whenever acculturation patterns are such not to accentuate the diversity between majority and minority cultures. It is normal that firms seek to achieve a certain degree of "sameness" in their strategy reflecting considerations for cost efficiency and due to the benefits that stem from economies of scale. Nevertheless, enduring and influential cultural differences are found to exert certain pressures on service firms' decisions towards more responsive acts (Okazaki and Mueller, 2007; Mattila, 1999). Therefore, whenever integration or assimilation portrays the dominant pattern of acculturation in a market, the differences between the diverse ethnic groups may not be salient enough and thus, firms tend to be better-off with the most cost-efficient option of "replication".

On the other hand though, if the outcome of the acculturation process is best characterised by "separation" then, clearly, a policy of "tailoring" or "invention" is favoured. For example, if a financial services firm identifies a substantial number of ethnic consumers who are separated from the majority, dominant culture (e.g. American, Canadian or British), then it will offer, e.g. tailored Islamic financial services (Rammal, 2010; Hearn et al., 2012; Volk and Pudelko, 2010) or tailored financial services to specific groups such as South Asians, African Americans, Hispanics etc. (Neilson and Chadha, 2008; Shanmuganthan et al., 2003). This is because culture-based differences not only financially justify a tailored approach but also, sometimes, this may seem "obligatory" due to strong cultural (e.g. religious) reasons. Moreover, studies (e.g. Fournier, 1998; Maldonado and Tansuhaj, 2002) have indicated that separated consumers not only consider tailored, ethnic brands as reminiscent of their home culture whose consumption enacts fond memories but also help in shaping consumption communities which lead to ethnic brand consumption through collective identification processes. Thus, we put forward the following proposition:

P4. The more the separated members of minority cultures in a multicultural market, the greater the degree of service tailoring or service invention (relative to service replication) in a services firm's offering.
Volume $27 \cdot$ Number $7 \cdot 2013 \cdot 515-525$

The fact is that with regards to marginalised consumers, empirical illustrations are strikingly scarce. Individuals in this category shape their identity and choices through social influences rather than cultural ones (Hutnik, 1991) and as such there is no engagement with culture-based offerings. Moreover, poor language skills or racial hostility and prejudice are vehicles that alienate these consumers from both their home and host contexts (Lindridge and Dhillon, 2005). Their often concurrent lack of social and economic capital accentuates these feelings of alienation and triggers the process of marginalization with shattered hopes (Üstüner and Holt, 2007). At the same time, often due to this alienation, ethnic individuals also exhibit behavioural standards or adopt ethical and political views which do not conform to the home ethnic norm and this process of alienation and rejection includes peers of their home culture, too (Iyer and Shapiro, 1999). Several of them may also voluntary reject these norms by default (Askegaard et al., 2005) due to, e.g. resistance to imposition of norms by elder ethnic community members. Thus, overall, marginalised feelings may emerge which result to a consumption behaviour which rejects both home and host cultural cues embedded in market offerings.

Therefore, limited and fragmented yet solid findings indicate that often, ethnic identity (home and host-related) is rejected and assumes no role in consumption preferences, because these preferences are simply shaped by other purely individual forces that are not linked to ethnicity (Firat, 1992). For example, this may be the adoption of a global consumer culture that transcends borders and ethnicities (Cleveland et al., 2009). Consequently, when the outcome of acculturation is one of marginalisation, service firms are not expected to identify a cultural basis for appealing to all ethnicities in a common way (replication) or, e.g. through an "invented" or "tailored" "ethnic" type of service. Whereas in the cases of integration, assimilation and separation, culture and/or ethnicity represent a highly significant force (facilitating a continuum of alternatives ranging from "replication" to "invention"), in the case of marginalisation, cultural elements assume a peripheral, unimportant or even negative role. As a result, other, non-cultural, normally service-specific factors will significantly influence firms' strategies. For example, a travel agent in the UK that already offers services which bear no reference to the British or any ethnic culture will replicate these services to minority, marginalized consumers. On the contrary, a travel agent that offers services which stress British tourists' idiosyncratic needs (e.g. accommodation services offering British breakfast) will resort to a more proactive, "inventive" behaviour when addressing to marginalized consumers. More specifically, we propose:

P5a. The more the marginalized members of minority cultures in a multicultural market, the greater the degree of service replication (relative to service tailoring and service invention) for firms offering "seamless" services with no cultural elements to majority consumers.

P5b. The more the marginalized members of minority cultures in a multicultural market, the greater the degree of "seamless service invention" (relative to replication and tailoring) for firms offering services with cultural elements to majority consumers. 
At this point, we clarify that the term "seamless service invention" denotes a new service offering with elements that do not make any reference to a particular culture i.e. an offering that aims to reflect marginalized consumers' expectations for a non-culture-based product.

\section{Conclusions}

The paper adopted a critical approach in order to stress the need for an acculturation perspective in multicultural services marketing. To the best of authors' knowledge, this is the only acculturation study in a services context that offers an analytical framework and propositions that can be used as a guide for multicultural, services marketing researchers and practitioners that see the whole market in a holistic fashion. Insightful yet limited services studies (e.g. Sharma et al., 2009; Perry, 2008) that utilize acculturation-related approaches have mostly done that by focusing on either specific ethnicities (e.g. Hispanics) or by focusing on the interface between customers and employees. Thus, they have not followed this broad approach of identifying implications for the marketing strategy of service firms that the current study proposes. We believe that this approach opens up the discussion about the role of acculturation in services contexts and can lead to empirically-laden investigations that explore the boundaries of our propositions. For example, propositions can be tested against service brands of high and low involvement (Torres and Briggs, 2005) or across value-expressive and utilitarian services contexts (Perry, 2008).

We must though acknowledge limitations of this paper. More specifically, several environmental forces may be equally or more meaningful in certain services contexts. For example, in health care services, age and income of users are highly relevant beyond a mere culture-driven approach. Future research could thus incorporate societal elements of culture (e.g. gender) and demographic characteristics in order to assess their moderating effect on suggested relationships promoted in this paper. Moreover, ethnicity or acculturation are just two of the forces that determine actual strategies by all types of firms and their influence is not only balanced against the influence of cost considerations (as proposition 3a suggests). Apparently, other forces can be also considered (e.g. corporate culture, international experience of executives, competitive dynamics) and be more meaningfully integrated in future attempts.

Concluding, we urge service researchers in multicultural markets to empirically investigate latter contexts through an acculturation lens. The phenomenon of interaction of ethnicities may be a dominant feature of the twenty-first century but nevertheless, implications for the marketing strategy of service firms are not yet well understood. Given the distinctiveness of some services sectors, "uncharted territories" in terms of insights and knowledge are expected to be even more than in non-services sectors. This lack of insights may be the result of the fact that what has mattered most in relevant investigations is the presence of multiple ethnicities rather than the ongoing interactions between them. We hope that arguments in this study manage to convince about the additional value of the latter for service firms.

\section{References}

Appadurai, A. (1990), "Disjuncture and difference in the global culture economy", Public Culture, Vol. 2 No. 2, pp. 1-24.

Askegaard, S., Arnould, E.J. and Kjeldgaard, D. (2005), "Postassimilationist ethnic consumer research: qualifications and extension", fournal of Consumer Research, Vol. 32, pp. 160-170.

Berry, J.W. (1997), "Immigration, acculturation and adaptation", Applied Psychology: An International Review, Vol. 46 No. 1, pp. 5-34.

Berry, J.W. (2003), "Conceptual approaches to acculturation", in Chung, K., Balls-Organista, P. and Marin, G. (Eds), Acculturation: Advances in Theory, Measurement, and Applied Research, American Psychological Association Press, Washington, DC, pp. 17-37.

Berry, J.W., Trimble, J.E. and Olmedo, E.L. (1986), "Assessment of acculturation", in Lonner, W.J. and Berry, J.W. (Eds), Field Methods in Cross-Cultural Research, Sage, Beverly Hills, CA, pp. 291-324.

Bhalla, A., Henderson, S. and Watkins, D. (2006), "A multiparadigmatic perspective of strategy: a case study of an ethnic family firm", International Small Business fournal, Vol. 24 No. 5, pp. 515-537.

Blankson, C. and Kalafatis, S.P. (2007), "Positioning strategies of international and multicultural-oriented service brands", Fournal of Services Marketing, Vol. 21, pp. 435-450.

Briggs, E., Landry, T.D. and Torres, I.M. (2010), "Services' influence on minority portrayals in magazine advertising", Fournal of Services Marketing, Vol. 24 No. 3, pp. 209-218.

Brubaker, R. (2001), "The return of assimilation? Changing perspectives on immigration and its sequels in France, Germany, and the United States", Ethnic and Racial Studies, Vol. 24 No. 4, pp. 531-548.

Burton, D. (2000), "Ethnicity, identity and marketing: a critical review", fournal of Marketing Management, Vol. 16, pp. 853-877.

Burton, D. (2002), "Towards a critical multicultural marketing theory", Marketing Theory, Vol. 2 No. 2, pp. 207-236.

Burton, D. (2009), Cross-Cultural Marketing: Theory, Practice and Relevance, Routledge/Taylor \& Francis Group, New York, NY.

Chattalas, M. and Harper, H. (2007), "Navigating a hybrid cultural identity: Hispanic teenagers' fashion consumption influences", fournal of Consumer Marketing, Vol. 24 No. 6, pp. 351-357.

Cleveland, M., Laroche, M., Pons, F. and Kastoun, R. (2009), "Acculturation and consumption: textures of cultural adaptation", International fournal of Intercultural Relations, Vol. 33, pp. 196-212.

Coleman, H.L.K. (1995), "Strategies for coping with cultural diversity", Counseling Psychologist, Vol. 23 No. 4, pp. $722-740$.

Dawes, J. (2009), "The effect of service price increases on customer retention", fournal of Service Research, Vol. 11 No. 3, pp. 232-245.

Devereux, G. and Loeb, E.M. (1943), "Antagonistic acculturation", American Sociological Review, Vol. 8 No. 2, pp. 133-147.

Feagin, J.R. and Feagin, C.B. (1996), Racial and Ethnic Relations, Prentice Hall, Upper Saddle River, NJ. 
Firat, A.F. (1992), "Fragmentation in the postmodern", Advances in Consumer Research, Vol. 19, pp. 203-205.

Fournier, S. (1998), "Consumers and their brands: developing relationship theory in consumer research", Fournal of Consumer Research, Vol. 24, pp. 343-373.

Freedman, A.L. (2001), "The effect of government policy and institutions on Chinese overseas acculturation: the case of Malaysia", Modern Asian Studies, Vol. 35 No. 2, pp. 411-440.

Furrer, O., Liu, B.-C. and Sudharshan, D. (2000), "The relationships between culture and service quality perceptions: basis for cross-cultural market segmentation and resource allocation", fournal of Service Research, Vol. 2 No. 4, pp. 355-371.

Geertz, C. (1963), Old Societies and New States, The Free Press, New York, NY.

Gibson, M.A. (2001), "Immigrant adaptation and patterns of acculturation", Human Development, Vol. 44 No. 1, pp. 19-23.

Gordon, M.M. (1964), Assimilation in American Life: The Role of Race, Religion, and National Origins, Oxford University Press, New York, NY.

Grandey, A., Rafaeli, A., Ravid, S., Wirtz, J. and Steiner, D.D. (2010), "Emotion display rules at work in the global service economy: the special case of the customer", fournal of Service Management, Vol. 21 No. 3, pp. 388-412.

Granovetter, M. (1985), "Economic action and social structure: a theory of embeddedness", American fournal of Sociology, Vol. 91, pp. 481-510.

Hearn, B., Piesse, J. and Strange, R. (2012), "Islamic finance and market segmentation: implications for the cost of capital", International Business Review, Vol. 21 No. 1, pp. 102-113.

Hutnik, N. (1991), Ethnic Minority Identity - A Sociological Perspective, Clarendon Press, Oxford.

Iyer, G.R. and Shapiro, J.M. (1999), "Ethnic entrepreneurial and marketing systems: implications for the global economy", fournal of International Marketing, Vol. 7 No. 4, pp. 83-110.

Jamal, A. (2003), "Marketing in a multicultural world: the interplay of marketing, ethnicity and consumption", European fournal of Marketing, Vol. 37 Nos 11/12, pp. 1599-1620.

Javalgi, R.G. and Martin, C.L. (2007), "Internationalization of services: identifying the building-blocks for future research", fournal of Services Marketing, Vol. 21 No. 6, pp. 391-397.

Jun, S.A., Ball, D. and Gentry, J.W. (1993), "Modes of consumer acculturation", in McAlister, L. and Rothschild, M. (Eds), Advances in Consumer Research, Association for Consumer Research, Provo, UT, pp. 76-82.

Keaveney, S.M. (1995), "Customer switching behavior in service industries: an exploratory study", fournal of Marketing, Vol. 59 No. 2, pp. 71-82.

Klemm, M. and Kelsey, S.J. (2004), "Ethnic groups and the British travel industry: servicing a minority?", The Service Industries fournal, Vol. 24 No. 4, pp. 115-128.

Korgaonkar, P., Karson, E. and Lund, D. (2000), "Hispanics and direct marketing advertising", fournal of Consumer Marketing, Vol. 17 No. 2.

LaFromboise, T., Coleman, H.L.K. and Gerton, J. (1993), "Psychological impact of biculturalism: evidence and theory”, Psychological Bulletin, Vol. 114 No. 3, pp. 395-412.
Volume $27 \cdot$ Number $7 \cdot 2013 \cdot 515-525$

Lambert, W.E. and Klineberg, O. (1967), Children's Views of Foreign People: A Cross-National Study, Appleton-CenturyCrofts, New York, NY.

Laroche, M., Kim, C. and Tomiuk, A.M. (1998), "Italian ethnic identity and its relative impact on the consumption of convenience and traditional foods", fournal of Consumer Marketing, Vol. 15 No. 2, pp. 125-151.

Lenartowicz, T., Johnson, J.P. and White, C.T. (2003), "The neglect of intracountry cultural variation in international management research", fournal of Business Research, Vol. 56 No. 12, pp. 999-1008.

Lerman, D., Maldonado, R. and Luna, D. (2009), "A theory-based measure of acculturation: the shortened cultural life style inventory", Fournal of Business Research, Vol. 62 No. 4, pp. 399-406.

Lindridge, A. and Dhillon, K. (2005), "Cultural role confusion and memories of a lost identity: how nonconsumption perpetuates marginalisation", Advances in Consumer Research, Vol. 32, pp. 408-414.

Lindridge, A. and Hogg, M.K. (2006), "Parental gatekeeping in diasporic Indian families: examining the intersection of culture, gender and consumption", fournal of Marketing Management, Vol. 22, pp. 979-1008.

Maldonado, R. and Tansuhaj, P. (2002), "Segmenting a local Latino market using Berry's acculturation taxonomy", in Broniarczyk, S.M. and Nakamoto, K. (Eds), Advances in Consumer Research, Vol. 29, Association for Consumer Research, Valdosta, GA, pp. 414-420.

Mattila, A.S. (1999), "The role of culture in the service evaluation processes", fournal of Service Research, Vol. 1 No. 3, pp. 250-261.

Miyazaki, A.D., Lassar, W.M. and Taylor, K.A. (2007), "Hispanic vs non-Hispanic response to online self-service tasks: implications for perceived quality and patronage intentions", Fournal of Services Marketing, Vol. 21 No. 7, pp. 520-529.

Neilson, L.C. and Chadha, M. (2008), "International marketing strategy in the retail banking industry: the case of ICICI Bank in Canada", Fournal of Financial Services Marketing, Vol. 13, pp. 204-220.

O'Guinn, T. and Meyer, T.P. (1984), "Segmenting the Hispanic market: the use of Spanish language radio", Fournal of Advertising Research, Vol. 23, pp. 9-16.

Ogden, D.T., Ogden, J.R. and Schau, H.J. (2004), "Exploring the impact of culture and acculturation on consumer purchase decisions: toward a microcultural perspective", Academy of Marketing Science Review, Vol. 3, pp. 1-22.

Olsen, B. (1995), "Brand loyalty and consumption patterns: the lineage factor", in Sherry, J.F. Jr (Ed.), Contemporary Marketing and Consumer Behavior: An Anthropological Source Book, Sage, Thousand Oaks, CA, pp. 245-281.

Omar, O., Kirby, A. and Blankson, C. (2003), "Acculturation and the influence of ethnicity on market orientation of African and Caribbean companies in Britain", The Service Industries fournal, Vol. 23 No. 4, pp. 81-97.

Oswald, L. (1999), "Culture swapping: consumption and the ethnogenesis of middle-class Haitian immigrants", fournal of Consumer Research, Vol. 25 No. 4, pp. 303-318.

Ownbey, S.F. and Horridge, P.E. (1997), "Acculturation levels and shopping orientations of Asian-American consumers", Psychology and Marketing, Vol. 14, pp. 1-18.

Palumbo, F.A. and Teich, I. (2004), "Market segmentation based on level of acculturation", Marketing Intelligence and Planning, Vol. 22 No. 4, pp. 472-484. 
Parekh, B. (2000), Rethinking Multiculturalism: Cultural Diversity and Political Theory, Macmillan, Basingstoke.

Peñaloza, L. (1994), “Atravesando fronteras/border crossings: a critical ethnographic exploration of the consumer acculturation of Mexican immigrants", fournal of Consumer Research, Vol. 21 No. 1, pp. 32-54.

Perry, V.G. (2008), "Acculturation, microculture and banking: an analysis of Hispanic consumers in the USA", Fournal of Services Marketing, Vol. 22 No. 6, pp. 423-433.

Phinney, J.S. (1990), "Ethnic identity in adolescents and adults: review of research", Psychological Bulletin, Vol. 108 No. 3, pp. 499-514.

Pires, G. and Stanton, J. (2000), "Marketing services to ethnic consumers in culturally diverse markets: issues and implications", fournal of Services Marketing, Vol. 14 No. 7, pp. 607-618.

Plath, D.A. and Stevenson, T.H. (2005), "Financial services consumption behavior across Hispanic American consumers", fournal of Business Research, Vol. 58 No. 8, pp. 1089-1099.

Poulis, K. and Poulis, E. (2012), "Poly-ethnic market orientation and performance: a fast-moving consumer goods perspective", fournal of Marketing Management, Vol. 28 Nos 5/6, pp. 609-628.

Poulis, K. and Yamin, M. (2009), "Tourism as a leverage of internationalization for consumer goods firms: a case study approach", Advances in International Marketing, Vol. 20, pp. 69-85

Poulis, K., Poulis, E. and Plakoyiannaki, E. (n.d.), "The role of context in case study selection: an international business perspective", International Business Review, in press.

Poulis, K., Yamin, M. and Poulis, E. (2012), "Domestic firms competing with multinational enterprises: the relevance of resource-accessing alliance formations", International Business Review, Vol. 21 No. 4, pp. 588-601.

Rammal, H.G. (2010), "Islamic finance: challenges and opportunities", fournal of Financial Services Marketing, Vol. 15, pp. 189-190.

Roosens, E. (1989), Creating Ethnicity: The Process of Ethnogenesis, Sage, Newbury Park, CA.

Seggie, S.H. and Griffith, D.A. (2008), "The resource matching foundations of competitive advantage: an alternative perspective on the globalization of service firms", International Marketing Review, Vol. 25 No. 3, pp. 262-275.

Sekhon, Y.K. and Szmigin, I. (2011), "Acculturation and identity: insights from second-generation Indian Punjabis", Consumption Markets \& Culture, Vol. 14 No. 1, pp. 79-98.

Shanmuganthan, P., Dhaliwal, S., Stone, M. and Foss, B. (2003), "Does ethnic focus change how banks should implement customer relationship management?", Fournal of Financial Services Marketing, Vol. 8 No. 1, pp. 49-62.

Sharma, P., Tam, J.L.M. and Kim, N. (2009), "Demystifying intercultural service encounters: toward a comprehensive conceptual framework", fournal of Service Research, Vol. 12, pp. 227-242.

Slater, S. and Yani-de-Soriano, M. (2010), "Researching consumers in multicultural societies: emerging methodological issues", fournal of Marketing Management, Vol. 26 No. 11, pp. 1143-1160.

Steenkamp, J.-B.E.M. (2001), "The role of national culture in international marketing research", International Marketing Review, Vol. 18, pp. 30-44.

Stevenson, T.H. and Plath, A.D. (2006), "Marketing financial services to Hispanic American consumers:
Volume $27 \cdot$ Number $7 \cdot 2013 \cdot 515-525$

a portfolio-centric analysis", fournal of Services Marketing, Vol. 20 No. 11, pp. 37-50.

Torres, I.M. and Briggs, E. (2005), "Does Hispanic-targeted advertising work for services?", fournal of Services Marketing, Vol. 19 No. 3, pp. 150-156.

Triandis, H.C., Kashima, Y., Emiko, S. and Villareal, M. (1986), "Acculturation indices as a means of confirming cultural differences", International fournal of Psychology, Vol. 2 Nos 1-4, pp. 43-70.

Unger, J.B., Gallaher, P., Shakib, S., Ritt-Olson, A., Palmer, P.H. and Johnson, A.C. (2002), "The AHIMSA acculturation scale: a new measure of acculturation for adolescents in a multicultural society", The fournal of Early Adolescence, Vol. 2 No. 3, pp. 225-251.

Üstüner, T. and Holt, D.B. (2007), "Dominated consumer acculturation: the social construction of poor migrant women's consumer identity projects in a Turkish squatter", Fournal of Consumer Research, Vol. 34, pp. 41-56.

Varki, S. and Colgate, M. (2001), "Role of price perceptions in an integrated model of behavioural intentions", fournal of Service Research, Vol. 3 No. 3, pp. 232-240.

Volk, S. and Pudelko, M. (2010), "Challenges and opportunities for Islamic retail banking in the European context: lessons to be learnt from a British-German comparison", fournal of Financial Services Marketing, Vol. 15, pp. 191-202.

Voss, G.B., Parasuraman, A. and Grewal, D. (1998), "The roles of price, performance, and expectations in determining satisfaction in service exchanges", fournal of Marketing, Vol. 62 No. 4, pp. 46-61.

Wallendorf, M. and Reilly, M.D. (1983), "Ethnic migration, assimilation and consumption", fournal of Consumer Research, Vol. 10, pp. 292-302.

Weber, M. (1968) in Roth, G. and Wittich, C. (Eds), Economy and Society, Vol. 1, University of California Press, Berkeley and Los Angeles, CA.

Yinger, J.M. (1985), "Ethnicity", Annual Review of Sociology, Vol. 11, pp. 151-180.

Zhang, J., Beatty, S.E. and Walsh, G. (2008), "Review and future directions of cross-cultural consumer services research", fournal of Business Research, Vol. 61, pp. 211-224.

\section{About the authors}

Konstantinos Poulis holds a $\mathrm{PhD}$ in International Marketing from Manchester Business School and is currently a Lecturer and Director of the M.Sc. in International Marketing and Entrepreneurship at the University of Essex. He publishes his work in the areas of marketing, international business and strategy researching services, consumer goods sectors and their interface. Konstantinos Poulis is the corresponding author and can be contacted at: poulisk@hotmail.com

Mo Yamin is Professor of International Business at Manchester Business School and an Honorary Research Associate at Uppsala University, School of Business. Previously, he has held senior visiting positions at the Copenhagen Business School and as a Hallsworth Fellow at the Victoria University of Manchester. He has published his work in several journals such as the fournal of World Business, Long Range Planning, International Business Review, Management International Review, and International Marketing Review among others.

Efthimios Poulis holds a $\mathrm{PhD}$ in Strategic Management from Manchester Business School where he has also been an 
Honorary Lecturer. He has a significant work experience with firms such as Johnson \& Johnson, Procter \& Gamble and as the general manager of the subsidiary of a multinational firm in the Philippines. He is currently the co-chair of the Strategic Management track in the British Academy of Management, the chair in the Dynamic Capabilities track in the European Academy of Management and a Senior Lecturer at the University of East Anglia.

\section{Executive summary and implications for managers and executives}

This summary has been provided to allow managers and executives a rapid appreciation of the content of this article. Those with a particular interest in the topic covered may then read the article in toto to take advantage of the more comprehensive description of the research undertaken and its results to get the full benefits of the material present.

Targeting market offerings to different ethnic groups is nothing new and is a perfectly normal way of going about businesses. If service companies have within the countries or regions in which they have their customer base a significant Hispanic or Asian population, for example, it makes sense to investigate any requirements they have which may be specific to and appropriate for their culture. Nothing remarkable about that. Business organisations do it all the time.

But, in doing so, are they taking a somewhat myopic approach? Are they ignoring the fact that in multicultural markets, pigeonholing groups of people as being different from others might be to ignore an important consideration? That being the fact there are many similarities between people of different cultural groups - i.e. long-term residents of a country and relative newcomers - and also many differences among people within ethnic groups.

For instance, some Pakistani consumers in the UK will be assimilated and "consume" the same entertainment services as native British consumers while other Pakistani consumers will stay attached to entertainment services that are reminiscent of their home culture. Fragmented yet increasing indications demonstrate that interaction between different ethnic groups and diverse acculturation outcomes may render ethnic identity less relevant for service firms, resulting in heterogeneous consumption behaviours within ethnic groups.

In "Multicultural markets and acculturation: implications for service firms", Konstantinos Poulis et al. say there appears to be a fundamental disconnect between consumer behaviour and services marketing literatures and they tackle the problem from the perspective of acculturation - i.e. the process of cultural change or maintenance whenever individuals from diverse cultures interact.

They say it can be inferred from the literature that interactions between ethnic groups are an ongoing, permanent process and that patterns of acculturation within ethnic groups are not homogeneous since "ethnic" consumers form their identities through diverse acculturation modes. On the other hand, the services marketing literature almost
Volume $27 \cdot$ Number $7 \cdot 2013 \cdot 515-525$

exclusively relies on an ethnic approach that is premised on an (often empirically invalid) high degree of intra-ethnic uniformity and sameness. Several studies, therefore, treat the ethnic group as an isolated segment, focusing on the distinctive features and the particular ethnic identification of, e.g. Hispanics.

The study focuses on intra-national ethnic diversity (INED) which is diversity stemming from the co-existence of different ethnic groups as permanent or long-term residence in one country. The authors do not underestimate the role of ethnicity. They acknowledge its value as they seek to tease out conceptually how interaction among ethnicities resulting in diverse acculturation outcomes may extend the boundaries of relevant services marketing studies.

In multicultural markets, an important question is whether service firms can treat on a common basis the ethnic groupings and perhaps benefit from cost savings arising from adopting a shared service "platform" across these subgroups. Potential cost advantages of a common approach would of course, be evaluated against perceived disadvantages arising from disregarding ethnic heterogeneities. In other words, for service firms with broad marketing horizons, the issue is one of using same, tailored or new strategies towards ethnic consumers.

By linking the pattern of INED with the acculturation process, the authors derive propositions regarding service firms' strategies by adopting the following definitions: service replication denotes offering members of minority cultures the same services as those offered to the majority culture. Service tailoring denotes tailored services compared to those offered to the majority culture. Service invention denotes new services compared to those offered to the majority culture.

Clearly, if service users tend towards an assimilation stance, then a policy of "replication" is favoured. For example, insights from the travel and media/entertainment sectors indicate that assimilated ethnic consumers in the UK and the US prefer the same travel services and listen to mainstream "Anglo" radio. This is not to claim that differences in ethnicity do not exist but, nevertheless, the voluntary decision of assimilated consumers to adopt the norms and consumption behaviours of the majority culture does not justify a "tailored" or "invention" approach, whereas a "replication" approach offers cost-related benefits.

Immigrants who demonstrate a "mutation" of their cultural narrative and adopt assimilationist behaviours are more proactive in shaping relationships with host-dominant culture, a stance that is also reflected in their consumption preferences. They tend to favour brands which are offered to the majority population since the latter acts as the main reference group for assimilated consumers' choices.

Consequently too-narrow an approach by service providers that ignores cross-ethnic interactions may lead to bypassing opportunities for more considerate market responses by a service firm.

(A précis of the article "Multicultural markets and acculturation: implications for service firms", Supplied by Marketing Consultants for Emerald.)

To purchase reprints of this article please e-mail: reprints@emeraldinsight.com

Or visit our web site for further details: www.emeraldinsight.com/reprints 